significant interaction between groups and testing sequences $F(1,32)=7.18, p<.05$.

\section{DISCUSSION}

The present results offer some indication of separate pictorial and verbal processing systems, since recognition was consistently reduced when tested within a different modality from that used during presentation. As shown in Table 1, however, this effect was localized primarily in the extremely poor pictorial recognition by the sentence group, with verbal recognition being nearly as high for the picture as the sentence group.

One possible interpretation of this asymmetrical transfer between pictorial and sentential modes would be based upon the greater and more detailed information contained in the present pictures than sentences. However, Nelson, Metzler, and Reed (1974) report no facilitation of delayed recognition of pictures containing more detailed information. Alternatively, this greater transfer from pictures to sentences could reflect a greater likelihood that Ss will generate verbal representations of pictorial stimuli, and/or a closer correspondence or similarity of S's verbal description to a picture from which it was generated. Sentential stimuli, on the other hand, appear likely either to produce no image at all or else a relatively impoverished image which is too discrepant to be judged equivalent to the actual photograph from which this sentence was generated. Such an interpretation of course, would be equally consistent either with separate or identical processing systems for pictorial and verbal material

Also requiring explanation is the present marked improvement in 48-h delayed over immed iate recognition for the modality not used during presentation. Although no feedback was given during recognition testing, Ss nonetheless may have been able to use the presentation therein of exactly corresponding sets of pictures and sentences to improve their recognition accuracy especially for the modality used for the first time during the immediate recognition test. Such "learning" could also account for the better overall recognition shown when the presented modality was tested first in the recognition sequence, thus enhancing the availability of these presented stimuli to facilitate recognition also of the corresponding stimuli in the nonpresented modality.

\section{REFERENCES}

Chase, W. G., \& Clark, H. H. Mental o perations i $n$ the comparison of sentences and pictures. In L. W. Gregg (Ed.) Cognition in learning and memory. New York: Wi ley, 1972.

Telson, T O Metzler, J., \& Reed, D. A. Role of details in the long-term recognition of pictures and verbal descriptions. Journal of Experimental Psy chology, 1974, 102, 184-186.

Paivio, A. Imagery and verbal processes. New York: Holt, Rinehart, \& Winston, 1971.

(R eceived for publication August 5, 1974.)

\title{
Long-delay learning in rats: A black-white discrimination*
}

\author{
SAM REVUSKY \\ Memorial University, St. John's, Newfoundland, Canada
}

\begin{abstract}
Rats can associate between events separated by intertrial intervals as long as several hours. For instance, they can learn that the type of food reward on one trial in a runway is correlated with whether running will be rewarded on the following trial. They also can learn that they will be rewarded if they alternate responses in a T-maze. In the otherwise similar experiments reported here, more traditional discriminative stimuli were used. Whether running down a runway was to be rewarded with sugar solution depended on whether the goalbox on the preceding trial, over $4 \mathrm{~min}$ ago, had been white or black. The rats learned this discrimination and retained it through an extinction phase.
\end{abstract}

Animals made sick as much as several hours after feeding exhibit bait shyness. This association of feeding cues with delayed sickness can occur without isolation of the animal from the many extraneous cues which naturally occur during a delay; these include uncontrolled sounds and visual stimuli as well as the movements of the animal itself. Nor is there any direct or indirect temporal continguity between the feeding cues and sickness (Revusky \& Garcia, 1970). Underlying this learning is a mechanism called stimulus relevance:

* Research supported by National Research Council of Canada Grant A-8271. B. T. Lett and Harry Taukulis edited this paper. F. Chapman, C. Gan, E. Harley, and K. Winter trained the rats. feeding cues become associated with sickness far more readily than other cues (Capretta, 1961; Garcia, McGowan, \& Green, 1972). As a result, the extraneous cues bound to occur during a long delay do not confuse the animal and prevent learning.

These findings challenge the empiricistic theory that there are no innate criteria for selective association. The belief that temporal contiguity (or near contiguity) is necessary for learning is a corollary of any explanation of selective association by strict empiricistic principles; for empiricism admits to no other means of selective association between dissimilar events imbedded in the hundreds of events bound to affect an animal during a 
time interval of even a few minutes. Thus empiricism implies that apparent associations over delays greater than a few seconds must be attributed to indirect association by contiguity through such mediating systems as lingering stimulus traces, chains of behavior, or secondary reinforcement. Such notions have dominated the psychology of learning throughout its history and have seemed to describe the results of traditional learning experiments so perfectly that no standard textbook of learning contradicts them.

This report demonstrates that rats can learn a black-white discrimination over a delay and hence that this empiricistic model breaks down not only for food selection, but in traditional learning situations. The goalbox of a runway was randomly black or white on different trials. Whether running was to be rewarded depended on which of these cues had been present on the preceding trial, which had terminated over $4 \mathrm{~min}$ earlier. The rat spent this delay in its home cage and it is to this feature of the procedure that its ability to learn was attributed. Presumably, there is an innate constraint upon association called situational relevance such that animals associate more readily between cues and consequences if both occur in the same situation (Capaldi, 1971; Revusky, 1971). Situational relevance implies that a rat removed from a runway and returned to it after a delay, should be able to associate cues which occurred in the runway prior to the delay with consequences which occur in the runway after the delay. Thus intertrial associations over fairly long delays should be possible as long as the rat remains outside of the runway during the delay. Cues which occur outside of the runway should not confuse the animal, just as cues which are not related to feeding do not confuse animals when they learn food aversions (Revusky, 1971).

The existence of situational relevance was inferred from the ability of rats to learn discriminations based upon the reward outcome of the preceding trial (Capaldi, 1971; Pschirrer, 1972) or the type of response emitted on the preceding trial (Petrinovich \& Bolles, 1957). However, an alternative explanation is that such cues are very salient for rats. No such claim can be made about the cues used here.

\section{METHOD}

\section{Subjects and Apparatus}

Four experimentally naive female Sprague Dawley rats were maintained at $80 \%$ of their free feeding weights during the experiment and for a number of weeks prior to it.

The runway was made of components supplied by the Hunter Manufacturing Company except for a black goalbox and Plexiglas gate to the goalbox. The sidewalls and top were of Plexiglas and the floors were steel grids. The inside height was $12.6 \mathrm{~cm}$ throughout and the inside width was $8.2 \mathrm{~cm}$ except in the black goalbox, where it was $12.6 \mathrm{~cm}$. The startbox was $30.2 \mathrm{~cm}$ long and the running alley was $136.1 \mathrm{~cm}$. All walls were painted flat gray except in the goalboxes. The white goalbox was identical to the startbox except for white tape covering its walls.
The black goalbox, made of wood, was $35.3 \mathrm{~cm}$ long. There were gates from the startbox to the running alley and from the alley to the goalbox. Speeds were measured by photocells which operated when the rats were $7 \mathrm{~cm}$ into the alley and $7 \mathrm{~cm}$ short of the end of the goalbox.

\section{Procedure}

Pretraining. During this phase, the rats were habituated to the goalboxes, but not introduced to any other part of the apparatus. There was a sequence of 108 trials administered at the rate of nine trials per day for 12 days. It was based on sets of 16 , of which 8 randomly selected trials were in the white goalbox and 8 were in the black goalbox. Each rat began at a different place in this randomized sequence of 108. Each goalbox placement lasted $60 \mathrm{sec}$ except during early trials when the rats were sometimes slow to drink in the goalbox. Since the rats were run in sequence, the intertrial interval was at least $3.5 \mathrm{~min}$. Discrimination training began during this phase, although no performance measures were feasible. On trials following $\mathrm{S}+$, a metal spout containing $10 \%$ (weight/volume) sucrose solution was available for the first $30 \mathrm{sec}$ and then removed. On trials following $\mathrm{S}-$, the spout was empty. The cue on the final trial of each day determined whether the first trial of the following day would be rewarded. Reward and nonreward occurred equally often in the $\mathrm{S}+$ and $\mathrm{S}-$ goalboxes due to a special constraint on the black-white sequence.

Training. There were 70 days of runway training. The procedure was identical to the pretraining procedure except that the rats ran to the goalboxes instead of being placed in them. Ten seconds after a rat was transferred by hand from its translucent plastic home cage to the startbox, a gate was opened so it could run to the goalbox. After $60 \mathrm{sec}$ in the goalbox, the rat was returned to its home cage. The minimum intertrial interval over which association was to occur was always over $4 \mathrm{~min}$ and usually 5 to $7 \mathrm{~min}$ (since it was necessary to switch goalboxes an average of twice during an intertrial interval). Note that each rat remained at a different point in the black-white sequence of 108 trials, so it could not discriminate on the basis of any odor trail left by some other rat.

Extinction. There were 12 days with five unrewarded trials per day. The black-white sequence was either BWWBB or WBBWW. Two rats, one black S+ and the other white S+, received the BWWBB sequence on Days $1,4,5,8,9$, and 12 of extinction and the other sequence on the remaining days; vice versa for the other two rats.

\section{RESULTS AND DISCUSSION}

Figure 1 shows that the rats learned the discrimination and retained it throughout extinction. For statistical purposes, mean speeds were obtained for each rat during acquisition, separately for each block of 10 days and for rewarded and unrewarded trials. A third factor in the ANOVA was whether black or white was St. The following effects yielded $p<.01$. Speeds were faster on rewarded than on unrewarded trials $(F(1,2)=$ 325.0) and this tendency became more marked over successive blocks $(F(6,12)=18.9)$. Speeds showed a statistical increase over blocks $(F(6,12)=5.9)$ reflecting the increase in speed from Block 1 to Block 2 apparent in Fig. 1. The triple interaction was significant $(F(6,12)$ $=5.5$ ): on the basis of later unpublished work with the same apparatus, I think this reflects an unlearned tendency of the rats to run faster after a trial terminating in the black goalbox than after a trial in the 


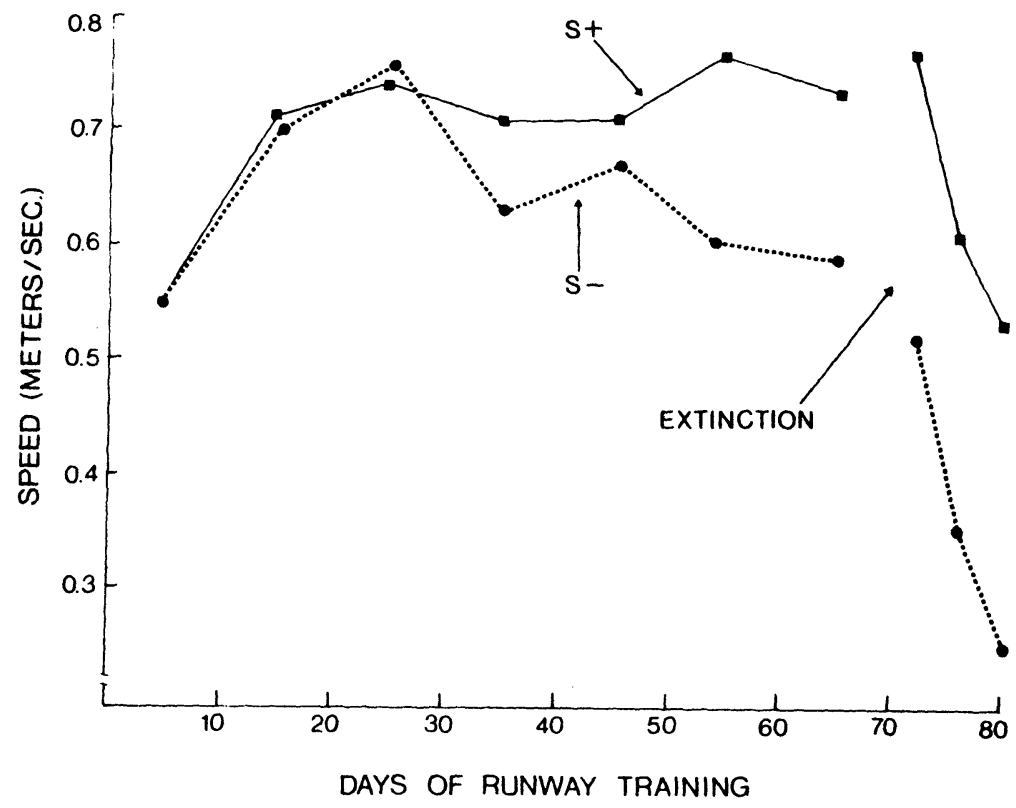

Fig. 1. Mean running speeds on $\mathrm{S}+$ and S- trials of rats subject to a black-white discrimination learning procedure with a 4-min stimulus-response delay. Reward was discontinued after Day 70.

white goal box; the result is that rats for which black is $\mathrm{S}+$ begin with some tendency to respond correctly and thus show less apparent learning over blocks. All other potential effects in the three-factor analysis of acquisition speeds yielded $\mathrm{p}>.10$. A similar ANOVA for the three 4-day blocks of extinction showed that speeds were higher on trials which would have been rewarded during acquisition $(\mathrm{F}(1,10)=53.8)$ and that speeds declined over blocks $(\mathrm{F}(2,10)=16.8)$; all other potential effects yielded $\mathrm{p}>.10$.

The main point is that the rats learned over a delay greater than $4 \mathrm{~min}$ without any indirect temporal contiguity. The delay was long enough to exclude visual afterimages of the goalbox while the rat was in the startbox. Mediating reactions were nearly certainly excluded by handling of the rats twice during the 4-min delay. Mediation by the environment was excluded because neither the home cage nor the runway conditions varied as a function of the color of the goalbox on the preceding trial. In fairness to readers, I must admit that earlier versions of this paper were rejected both by the Journal of Comparative and Physiological Psychology and by Learning and Motivation and that one parenthetical editorial remark made some sense: cues other than brightness, such as the difference in the size of the two goalboxes and the difference in the materials of which they were made, may have helped the rats learn the discrimination. But I do not think that this possibility detracts much from the importance of the results given the powerful tradition that a delay of over a few seconds prevents learning in the absence of indirect temporal contiguity.

An outline of the present experimental paradigm corresponds to that of traditional delayed reaction experiments because the delay was between a cue and the opportunity to respond. In the delay of reward situation, which has traditionally been regarded as basically different from the delayed reaction situation, Lett (1973, 1974, in press) and Denny (1974) have used removal of the rat from the apparatus to obtain learning with delays of up to an hour. Although such results are unprecedented in traditional learning situations and are entirely contradictory to traditional empiricistic learning theories, they had been expected on the basis of my theory of long-delay learning (Revusky, 1971).

\section{REFERENCES}

Capaldi, E. J. Memory and learning: a sequential viewpoint. In W. K. Honig and H. James (Eds.), A nimal Memory. New York, Academic, 1971.

Capretta, P. J. An experimental modification of food preferences in chickens. Journal of Comparative \& Physiological Psychology, 1961, 54. 236-242.

Denny, M. R. Recent explorations with a T-maze: women's lib long delays and all that. Paper delivered at the 46th annual meeting of the Midwestern Psychological Association, Chicago, 1974.

Garcia, J. McGowan, B. K., \& Green, K. F. Biological constraints on learning. In A. H. Black \& W. F. Prokasy (Eds.), Classical conditioning II: Current theory and research. New York: Appleton-Century-Crofts, 1972.

Lett, B. T. Delayed reward learning: disproof of the traditional theory. Learning and Motivation. 1973. 4. 237-246.

Lett, B. T. Visual discrimination learning with a 1-min delay of reward. Learning \& Motivation, 1974, 5, 174-181.

Lett, B. T. Long-delay learning in the T-maze. Learning \& Motivation, in press.

Potrinovich, L., \& Bolles, R. C. Delayed alternation: Evidence for symbolic processes in the rat. Journal of Comparative \& Physiological Psychology, 1957, 50, 363-365.

Pschirrer, M. E. P. Goal events as discriminative stimuli over extended intertrial intervals. Journal of Experimental Psychology, 1972, 96, 425-432.

$R$ evusky, $S$. The role of interference in association over a delay. In W. K. Honig and H. James (Eds.), Animal memory. New York, A cad emic, 1971.

Revusky, S., \& Garcia, J. Learned associations over long delays. In G. H. Bower (Ed.), The psychology of learning and motivation: advances in theory and research. Vol. 4, New York, Academic, 1970.

(Received for publication August 21, 1974.) 